\title{
Research on Full Cycle Risk Management of Logistics Real Estate Based on Risk Matrix
}

\author{
Yueying Wang ${ }^{1, *}$
}

\author{
${ }^{1}$ School of Economics and Management, Beijing Jiaotong University, Beijing 100044, China \\ *Corresponding author. Email: 19125505@bjtu.edu.cn
}

\begin{abstract}
Through literature research and expert interview, this paper sorts out the risk factors of logistics park projects in the whole life cycle, constructs the evaluation index system of investment risk factors, evaluates the risk level by using the risk matrix method, formulates corresponding countermeasures for different risk factors, and forms the investment risk management mechanism. This paper aims to help logistics real estate developers identify risks in advance and effectively avoid risks in the investment process.
\end{abstract}

\section{Keywords: risk matrix, full cycle, logistics real estate, risk, risk indicator}

\section{INTRODUCTION}

The concept of logistics real estate was first put forward and put into practice in the 1980s in the United States, usually referring to warehousing equipment such as logistics distribution centers and logistics industrial parks. The modern logistics real estate mainly takes the logistics park as the core carrier to provide the services such as leasing, operation and distribution of the park, etc. Logistics real estate emerged in China in 2003. With the rapid economic growth, the logistics industry continues to develop, and the demand for logistics infrastructure is also increasingly strong. Under the contradiction between supply and demand, the vacancy rate of Logistics Park continues to decline, and the rent increases year by year. Compared with commercial real estate and residential real estate, Logistics Real Estate also has higher investment value.

After more than ten years of development, the main body of logistics real estate investment and construction has gradually diversified, mainly in government investment, enterprise investment, joint investment of government and enterprise, etc. Because the concept of logistics real estate is imported, the earliest to open up the domestic market for foreign enterprises, such as Pross, Jiamin, Ambo, Fengshu occupied the forefront of the logistics real estate pattern. In recent years, private enterprises represented by Yupei and Baowan have also risen rapidly and achieved market breakthrough through capitalization operation. With the real estate entering the stock era, real estate enterprises race to accelerate the pace of transformation and upgrading, Vanke established Wanwei Logistics Company as early as 2015, and acquired Pross China in 2017, becoming the largest domestic logistics developers. In addition, Alibaba, Jingdong and other e-commerce platforms and financial institutions such as real estate have also entered the real estate logistics.

Logistics real estate is a capital- intensive industry, and the return on investment cycle is long, and in such a large number of participants, the fierce competition stage, the investment risk research and attention is particularly important.

\section{RESEARCH ON LOGISTICS REAL ESTATE PROJECT RISK IN CHINA AND FOREIGN COUNTRIES}

Based on the theory of real estate financing of agricultural products logistics, Jiang Xuesong analyzes the factors that affect project financing, and Chai Ying analyzes the financing problem under the external bond mode of enterprises.

About the logistics real estate investment risk is the most studied problem, domestic and foreign scholars through different methods, different angles of multilevel exploration and research, there are more mature theory. Xu Jiwei divided the investment risk into 6 categories, and established the investment risk model of logistics real estate with AHP. Yuan Lin established the risk evaluation system with grey relational analysis and fuzzy comprehensive evaluation method of AHP.

Based on the research of domestic and foreign scholars, the risks of logistics real estate in the whole life cycle of our country are complex and diverse, with different characteristics. To correctly grasp these characteristics is of great significance for risk assessment and evasion:

The risks of logistics real estate are significant in stages, and the types and impact of risk factors will 
change over time and in the project process. For example, at the feasibility study stage, the uncertainty of government

policy is greater than other risks and increases as the project progresses and peaks at the end of the feasibility study. In the construction stage, the technical risk becomes the main risk factor, presents the upward trend.

The risks of logistics real estate are diversified. The development of logistics real estate in our country is not mature and perfect. The development and operation modes of logistics real estate are complex and diverse. Different modes face different risks and the project cycle is long. From investment planning to operation management, there are many risk factors in each stage of the project, and the diversity of risk factors is more significant because of the difference of economic development level in different regions.

\section{RISK MANAGEMENT MECHANISM}

\section{A. Risk assessment system design}

There are three steps in the process of risk management. First, establish a risk management mechanism, then assess the risk of the management mechanism, and finally respond to the results of risk assessment. Risk assessment includes three processes: risk identification, risk analysis and risk assessment. The common methods are risk index, brainstorming, principal component analysis and risk matrix. The initial risk matrix includes the column of risk factors, the column of risk impact, the column of risk probability and the column of risk grade, as shown in "Table I", "Table II" and "Table III".

TABLE I. RISK CONSEQUENCE CLASSIFICATION

\begin{tabular}{|c|l|l|}
\hline $\begin{array}{l}\text { Risk } \\
\text { severit } \\
\text { y level }\end{array}$ & $\begin{array}{l}\text { Grade } \\
\text { description }\end{array}$ & \multicolumn{1}{|c|}{ Have consequence } \\
\hline I & $\begin{array}{l}\text { Extremely } \\
\text { low }\end{array}$ & $\begin{array}{l}\text { If the risk occurs, the investment will } \\
\text { exceed the estimated 5\%, but the project } \\
\text { can still be completed. }\end{array}$ \\
\hline II & Low & $\begin{array}{l}\text { If the risk occurs, the investment will } \\
\text { exceed the estimated 5\%-15\%, but the } \\
\text { project can still be completed. }\end{array}$ \\
\hline III & Medium & $\begin{array}{l}\text { If the risk occurs, the investment will } \\
\text { exceed the estimated 15\%-30\%, but the } \\
\text { project can still be completed. }\end{array}$ \\
\hline IV & High & $\begin{array}{l}\text { If the risk occurs, the investment will } \\
\text { exceed the estimated 30\%-50\%, but the } \\
\text { project can still be completed. }\end{array}$ \\
\hline V & $\begin{array}{l}\text { Extremely } \\
\text { high }\end{array}$ & $\begin{array}{l}\text { If the risk occurs, it will lead to the } \\
\text { suspension of the project and investment } \\
\text { failure. }\end{array}$ \\
\hline
\end{tabular}

TABLE II. RISK PROBABILITY LEVEL

\begin{tabular}{|l|l|l|}
\hline $\begin{array}{l}\text { Risk } \\
\text { probability } \\
\text { level }\end{array}$ & $\begin{array}{l}\text { Probability } \\
\text { range /\% }\end{array}$ & Grade description \\
\hline A & $91-100$ & Occur frequently \\
\hline B & $61-90$ & May happen \\
\hline C & $41-60$ & Happens ocasionally \\
\hline D & $11-40$ & Not easy to happen \\
\hline E & $0-10$ & Almost never happens \\
\hline
\end{tabular}

TABLE III. RISK LEVEL EVALUATION CONTROL

\begin{tabular}{|l|l|l|l|l|l|}
\hline $\begin{array}{l}\text { Risk probability } \\
\text { range }\end{array}$ & I & II & III & IV & V \\
\hline A & H & H & H & H & M \\
\hline B & H & M & M & M & M \\
\hline C & H & M & M & M & L \\
\hline D & H & M & M & M & L \\
\hline E & M & M & L & L & L \\
\hline
\end{tabular}

\section{B. Project risk factor identification}

Risk identification is the basis of risk management. It is usually possible to list risk sources, classify or group risks, and state symptoms of risk. According to the fifth investigation report of 1638 logistic parks in China, this paper looks up the difficulties and problems in the life cycle of logistic park projects and sorts out the risk factors affecting the investment of logistic real estate projects. According to the whole life cycle of logistics park project, the development and construction of logistics park is divided into three stages: investment planning, construction and operation management. Delphi method is used to identify the risk factors at each stage through in-depth discussions among industry experts.

From the perspective of financial dimension, logistics real estate is a typical capital-intensive industry with huge investment amount, long investment return period, and high requirements on capital strength, investment capacity, financing capacity and other capital operation capacity, and it often needs continuous operation to make profits. The risks in this dimension are mainly reflected in investment capacity risk, financing capacity risk, turnover capacity risk, profitability risk and solvency risk, reflecting the risk concerns of shareholders, operators, creditors, employees and other stakeholders of logistics real estate enterprises in the process of development and operation of logistics real estate.

\section{Risk rating}

Risk level determination is an important link in the whole cycle risk management of logistics real estate project. It scientifically quantifies the scope and probability of risk impact. In the process of confirmation, experts in the field of logistics real estate need to make a reasonable judgment and evaluation according to the effective information of the project and 
previous experience. On this basis, according to the results of expert evaluation, the comparison table can determine the various risk levels of the project.

\section{Risk response}

Logistics real estate project risk response mainly includes risk aversion, risk dispersion and risk transfer. According to the specific circumstances of the project itself to develop different measures and methods to reduce the risk to a minimum.

1) Risk avoidance: On the basis of risk analysis and evaluation, investors shall determine the investment mode according to their own risk resistance ability and the appropriate risk coefficient. In the early stage of the project, the risks at all levels shall be fully recognized, and evasion measures shall be taken to avoid possible losses for the risks that occur to a large extent and are too harmful to the project.

2) Risk diversification: Spread the risk by looking for multiple firms to subcontract or co-contract. Logistics real estate warehousing project is characterized by a large number of subjects, long investment cycle, large scale, the main risk will be divided into several at the same time, in order to reduce risk.

3) Risk retention: When the risks cannot be changed and other methods and measures for dealing with the risks cannot be found, the enterprise can only bear the losses caused by the risks with its own capacity, and shall formulate a response plan to resist risks by taking measures such as preventing or reducing the risks and losses. In the process, the impact of risk factors on the project should be made clear so as to make a relatively reasonable plan.

4) Transfer of risks: In practical application, the project risk brought by different projects will be different, the same project risk will also be affected by external environment and other factors are not the same. Therefore, it is necessary to classify project risks according to the nature of different projects and formulate corresponding risk response strategies. In general, they shall be selected in the following order: whether the investment risk factors can be avoided in priority, and whether the risks can be transferred if such risk factors cannot be avoided; if it is difficult to realize the risk transfer, then they shall formulate risk response measures to curb the probability of risk occurrence or reduce the consequences at the time of risk occurrence; if it is impossible to curb the occurrence of risk events or the economy of the containment measures is poor, they shall accept risks and strengthen the monitoring and prevention of risk events.

\section{ApPliCATIONS}

\section{A. Project overview}

The article takes the development and construction project of the Jingbei Smart Logistics Park as the research object and conducts case analysis. The project has a construction area of 462,200 square meters and a total investment of about 120 billion yuan. It is planned to be developed in three phases, with an investment of 320 million yuan in the first phase, covering an area of $4000 \mathrm{mu}$. Mainly built exhibition centers, logistics distribution, complete vehicles, spare parts storage, and finally completed industrial cluster projects including ecommerce industrial park, high-end biomedicine trade service center, modern international integrated industrial park and high-end manufacturing service industry as the core of the park in the park

As the builder, manager and operator of the logistics park, the company attaches great importance to the realization of strategic objectives and the control of business risks, and pays attention to the whole life cycle risk management in business activities.

\section{B. Full-cycle risk identification and evaluation}

In the project planning stage, through expert interviews and expert scoring, the risk impact degree and occurrence probability of the project's full-period risk factors are evaluated. According to the statistical expert evaluation results, the comparison table is used to obtain the full-cycle risk matrix of the logistics real estate project. The final result is that there are $3 \mathrm{H}, 5 \mathrm{M}$ and $7 \mathrm{~L}$ risks respectively, and the specific content is shown in the table.

\section{Investment risk response measures}

According to the results of the risk grade evaluation, the project risk management plan was formulated after joint research by the construction party and experts.

Attention should be paid to risk factors with an evaluation level of $\mathrm{M}$ or higher: evasion measures are formulated for evasionable risk factors; risk transfer plans are formulated for risks that are difficult to evade but transferable, such as the use of real options for interest rate risk to transfer risks In view of construction technology risks, general contracting construction mode can be adopted to transfer risks.

It is required to take risk response measures or strengthen risk monitoring for risk factors with an evaluation level of L. For example, for risk factors that cannot be avoided and transferred such as tax policy risks, the construction unit should reserve basic reserve funds with sufficient flexibility. Respond to the impact of national tax policy adjustments on project investment 


\section{CONCLUSION}

This paper has constructed a modern agricultural industrial park project investment risk management mechanism, and discussed the application of risk matrix method for project investment risk assessment. Research shows that the project full-cycle risk assessment method based on the risk matrix method has outstanding features such as convenience, objectivity and effectiveness. It can identify investment risk factors and quantify the probability and impact of risk, scientifically determine the risk level, and facilitate the construction unit to formulate risk management in advance The plan plays an important role in strengthening investment management of construction units.

\section{References}

[1] L.Yuan, Study on Investment risk of Logistics Real Estate. Chongqing University, 2011

[2] X.R. Fan, Research on the Layout Planning of Multi-service Logistics Park, Beijing Jiaotong University, 2017

[3] X.Y. Wu. Research on project risk management of northwest coal logistics park in Wuwei, Xian Keji University, 2018

[4] X.W. Gong, Y. Wang, Empirical Research on Risk Identification and Assessment of Logistics Real Estate. Technical Economics and Management Research, vol. 5, pp. 1216.

[5] Y. Li, W.D. Yue, R isk Management Mechanism of Modern Agricultural Park Project Investment Based on R isk Matrix Method. Agricultural Engineering, vol. 9,no.12, pp. 135-138.

[6] C.J. Jing. Logistics Real Estate Project Risk Management. LOGISTICS ENGINEERING AND MANAGEMENT,vol.33, no. 5,pp.30-31, 2011

[7] X.B. Feng, Research on risk evaluation of Logistics real estate projects in Small and medium-sized cities. Chongqing Jiaotong University, 2018 